\title{
The Effect of Persian L2 Learners' Proficiency Level on their Degree of Observing Subjacency in $\mathrm{L} 2$
}

\author{
Behrouz Nouri Samani (Corresponding Author) \\ Department of Foreign Languages, Khorasgan Branch, Islamic Azad University, Isfahan, Iran \\ Email: Behrouznourisamani@yahoo.com \\ Ahmad Reza Lotfi \\ Department of Foreign Languages, Khorasgan Branch, Islamic Azad University, Isfahan, Iran
}

\begin{abstract}
This experimental study examined how L2 learners' L2 proficiency level affected their performance in GJ tasks while rendering WH-questions using a repeated measures design. Participants included 60 female Persian EFL participants from the Islamic Azad University - Khorasgan Branch - at two levels of English proficiency (i.e. High- and Low-Intermediate levels). The instruments (i.e. explicit written, implicit written, oral stimulus, and no stimulus GJ tasks) involved rendering different cases of subjacency in four consecutive time settings for four weeks per each GJ task by each participant. The results revealed that L2 proficiency level is of no significant effects on the $\mathrm{L} 2$ learners' performance on WH-questions.
\end{abstract}

Index Terms - explicit written GJ task, implicit written GJ tasks, no stimulus GJ task, oral stimulus GJ task, repeated measures design, subjacency

Research has shown the importance of syntax ever since the influence of Chomsky's ideas on linguistics. A syntactic operation termed merger exists in syntax which views languages to have a potentially infinite number of sentences and allows words, phrases, and clauses to form sentence structures; in addition, it leads to the formation of grammatical sentences in all languages. Such structures are projections of overt constituents such as words, phrases, and clauses. Moreover, they consist of covert, null, and empty constituents. An important aspect of syntactic structures is termed the empty category, which is of immense significance in the formation of WH-questions. Trace is a sample of empty categories resulting from different movement types. In the 1970s and 1980s, a moved constituent was judged to leave a trace at its extraction site, and traces were considered to resemble pronouns in specific cases. Moreover, such a moved constituent would form a chain with its trace; that is, the moved constituent would be the head of the chain, and its trace would be the foot of the chain. In 2000s, traces were reformulated in terms of copying according to which units in one position were duplicated in another (Matthews, 2007). The binary-branching tree diagrams represent syntactic structures and consist of three positions (i.e. specifier, head, and complement) (Radford, Atkinson, Britain, Clahsen \& Spencer, 2009).

Sentence syntactic structures are independent of their related meanings, hence the ability to study such syntactic structures independently of their associated semantic contents. However, the sentential ordering of syntactic structures, according to Chomsky, only permits specific orderings, hence the ungrammaticality of some sentences. Syntactic computation, which is a major property of human language faculty, is structure-dependent. In addition, humans' language faculty can compute and build such binding relations as c-command and indexation that are parts of the resources constituting their language faculty (Isac \& Reiss, 2008). Syntax is a universal combinatory system of humans' linguistic competence, which is an integral part of language faculty and constitutes the basis for all human language instantiations (Ramchand, 2008).

Most recent studies that have investigated the issue of L2 proficiency have found evidence in support of the hypothesis that higher L2 proficiency levels foster L2 learners' awareness of grammatical accuracy and represent more accurate sentence-level syntax (Savignon, 2005). These somewhat controversial findings in the existing research prompt further investigations about the degree to which L2 learners' proficiency levels in L2 influence their grammatical accuracy in Grammaticality Judgement Tasks. The present study aimed to examine the effect of L2 proficiency level on L2 Learners' performance in GJ tasks when rendering WH-questions. GJ tasks were selected as the elicitation instruments in this study because they are of wide-spread use across different academic settings.

Therefore, the theoretical framework underlying this study was derived in view of four main aspects of theory, research, generative models, and the operational definition of the concepts used in this study: (a) The body of literature about the influence of L2 proficiency level on the grammatical performance of L2 learners in terms of WH-questions in GJ tasks; (b) the phenomenon of High- and Low-Intermediate L2 learners' performance on different cases of subjacency in English WH-questions using four different types of GJ tasks within a repeated measures design as an insufficiently studied scientific domain in SLA; (c) the generative models of language and grammar forming the basis of 
research in SLA; and (d) the operational definitions of such issues as WH-movement, WH-movement in English and Persian, and GJ tasks. Therefore, before presenting the study and its findings, its theoretical and empirical background will be briefly outlined.

\section{LITERATURE REVIEW}

Much research in subjacency (e.g., Schachter, 1988) has indicated that different L2 learners' access to the UG principle of subjacency and the proper observance of it in GJ tasks can be either attributed to UG or the effect of L2 learners' L1. In addition, such researchers have only tested their L2 learners' knowledge of subjacency under uniform and like conditions and have oftentimes concluded that subjacency is a part of the L2 learners' unconscious knowledge, or rather grammatical proficiency, although it may not be consistently obeyed. Other researchers (e.g., Bley-Vroman, Felix \& Ioup, 1988) have only emphasized UG availability while rendering GJ tasks on subjacency and have concluded that this availability of UG is, at times, only overridden by other factors in performance (White, 1990).

In another experiment, researchers (e.g., Schachter, 1989, 1990) have indicated that learners fail to recognize violations of UG principles, such as subjacency, unless these principles also operate in their L1; therefore, Korean and Chinese speakers cannot recognize subjacency violations in English, whereas Dutch speakers can (White, 1996).

Gass and Mackey (2000) focused on the subjects' answers to GJ tasks and asserted that such answers reflected two issues: (a) It was either the case that subjects were following a developmental path; or that (b) they were constrained by their native language patterns. In addition, subjects' answers might have reflected both of these issues. As for subjects' proficiency levels, it should be noted that "the limited proficiency of learners operating in their L2s may influence the content of the recalls". That is, it is possible for the students not to be able to understand or even verbalize the full extent of what they were thinking (p.98).

In a study, Hawkins (2001) believed that L2 learners' performance data could be an indirect reflection of their grammatical competence because such data could deceive us into thinking that L2 learners knew a lot or less than expected. Performance data were also complex because samples involved more than one grammatical property.

Some researchers (e.g. White, 1989) believed that the learners' interim competence was accounted for by using an abstract rule system, but a difference existed between an L2 learner's competence and his performance; that is, when an L2 learner used his L2 knowledge, as in a GJ task, he reflected not only his interlanguage but also his performance variables that were not necessarily considered to be parts of his competence. The fact that we used a form differently in different settings was not part of our competence, it actually referred to the performance variables. One of the major reasons for the use of GJ tasks was that competence could not be directly tapped and that it was, actually, the performance aspects that could give us insights into the subjects' competence such as performance on GJ tasks.

In a study on Chinese speakers of L2 English, Ellis (1991) asked the students to take part in two tasks; that is, all the Chinese subjects were, first, administered a standard GJ task with 40 sentences, and, afterwards, eight of the subjects were asked to perform an introspective individual Speak-Aloud GJ task containing 10 of the previously administered 40 sentences. Having analyzed the section, Ellis identified such strategies as feel, rehearsing, rehearsing alternate version, trying to access explicit knowledge, using analogy, evaluating a sentence, and guessing to be used by L2 learners while taking the GJ tasks.

Since most students had answered the questions rapidly, Ellis came to the conclusion that the intuitive strategy of feel had been extensively made use of in GJ tasks. Furthermore, another issue that was evident was lack of consistency between the subjects' responses in the first task as opposed to their responses in the second task.

In a study, Han and Ellis (1998) did a factor-analysis on a series of tests to find out which one could be taken into account as a pure measure of implicit or explicit measure. The tests tested were Oral Production, Grammaticality Judgement, Metalinguistic Knowledge, TOEFL and SLEP. They found that none of the tests could be taken to be a pure measure of either implicit or explicit knowledge; however, this result could not be safely generalized because the focus was only on one structure (viz. verb complements) (Dekeyser, 2003).

\section{A. Generative Models of Language and Grammar}

Grammar is a single and complex unit that generates syntactic structures and assigns representations to such structures at two levels, namely phonological form (PF) and logical form (LF). Different opinions have existed about the grammar structure since the start of generative linguistics in the 1950s; however, all such different opinions have agreed that grammar is abstract and is not located in space or time. A speaker's grammar is his knowledge object because such a grammar has information about his language.

In addition, such a grammar is represented in the speakers' minds because grammars serve in the speaker/ hearers' mental processes and mediate the production and perception of speech. Moreover, the study of grammar is highly effective in understanding the nature of the linguistic ability of humans because when people speak a language, they follow its formal rules, such as rules of syntax (George, 1989).

Every language is made up of linguistic ingredients, and such ingredients are arranged based on a set of rules called grammar. One part of grammar that deals with the sentence structures is called syntax. As such, the major concern of syntax is word order, and those linguists who work within generativism have taken into account syntactic universals as 
the best piece of evidence for UG. Such universals have even been of constructive contribution in SLA research because they apply to all language types (Magni, Scalise \& Bisseto, 2009).

Most generative grammarians belie that grammars should fully characterize competence and not performance; in addition, they believe that grammars should be psychologically relevant. A particular generative grammar pertains to the mind/brain state of the person who speaks a language. Every human being can learn a language using little explicit instruction. This fact suggests that humans are genetically endowed with a mental organ that is capable of acquiring languages, a scientific point that is known as the argument from the poverty of the stimulus. Research in generative grammar has revealed a lot about language structure, particularly in such areas as binding principles, filler-gap dependencies, and island constraints.

Island constraints constrain the positions in which filler items and gaps may appear, such as the cases where the gap may not be in a relative clause if the filler item is outside of it. The same constraints hold for gaps internal to embedded questions. In addition, a gap cannot appear in co-ordinate conjoined structures unless all conjuncts have gaps that are filled by the same filler item. Noam Chomsky's work has dominated the field of generative theories of grammar throughout its history (Wasow, 2003, pp. 297-300).

All of the grammar theories developed since Chomsky's seminar in the 1950s deal with the extensions of the contextfree (phrase structure) grammar (CFG). CFG consists of two parts: (a) A lexicon that comprises a list of words with their relevant grammatical categories (i.e. lexical categories); and (b) a set of rules that are called phrase structure rules; that is, a phrasal category (i.e. A) may consist of "any string of lexical and/or phrasal categories". It is possible for phrases to be embedded within other phrases and result in the recursive character within a characteristic that is needed to generate infinite languages. In 1950s and early 1960s, Chomsky, Postal, and others criticized CFGs on grounds of lacking the required "descriptive power to account for all of the syntactic regulations of natural languages", a criticism that was generally accepted (Wasow, 2003, pp. 301,302).

From the 1950s onwards, Chomsky developed TG as a form of generative grammar that consisted of some rules for transformations. Such rules, or rather T-rules, consisted of two parts, that is a structural description (SD) and a structural change (SC). In 1970s, a theory was used to properly recognize TG from other grammar types, namely standard theory or aspect theory (Matthews, 2007).

Gass and Selinker (2008) maintain that innateness is, according to nativists, involved in, at least, some language learning aspects. Having seen it this way, researchers noted two positions: (a) General nativism; and (b) special nativism. The special nativist approach is known as UG. Within UG theory, language consists of abstract invariable principles that characterize the core grammars of all languages and variable parameters that vary across languages. "UG is postulated as an innate language facility that limits the extent to which languages can vary". Hence, an innate language faculty exists in learners (i.e. children) that enables them to obtain adult grammar complexities because they know specific grammar properties that are not learnable from input (i.e. poverty of the stimulus) (p. 161).

Matthews (2007) holds that principles and parameters theory (P\&P) was the dominant model practiced from the early 1980s onwards and was developed by Chomsky. Two versions of the P\&P model are GB theory that was developed in the 1980s, and its reformulated form that emerged in the 1990s (i.e. MP). P\&P model is the theory of UG, namely the genetically inherited mental structures that form the bases of language development. GB is a version of Chomsky's P\&P theory that was named by Chomsky's followers in 1981 after Chomsky's lectures on GB. The primary objective for the development of P\&P-based MP, which was developed in the early 1990s by Chomsky, was to develop a simplified version of GB theory. Within minimalism, a grammar is viewed as relating two interface levels (i.e. PF and LF), which are the interfaces with different performance systems. Performance systems are those mental systems that interface with grammar at two separate levels, namely PF and LF. PF and LF must be interpretable by the performance systems. The aim has been to eliminate other levels of representation such as deep and surface structures and simplify the computational system (Matthews, 2007).

\section{B. WH-Movement}

Interrogatives are of complex syntactic structures and are of two types (i.e. closed and open). Whereas the former shows subject-auxiliary inversion, the latter shows the fronting of the nonsubject interrogative phrase that involves a WH-word with the ability to trigger subject-auxiliary inversion, and, as a result, the occurrence of WH-movement. In addition, such interrogatives can be in the form of multiple WH-questions (Collins, 2006). Interrogatives are multiclausal sentences that are syntactically related to each other via subordination because their clauses show unequal syntactic status (Huddleston \& Pullum, 2006).

An important point in WH-questions is movement. Movement is a process in generative grammar and a syntactic operation by which constituents move and leave behind silent trace copies. Movement, which was formulated from the early 1970s, "move[s] as few constituents as possible the shortest distance possible" (Radford et al., 2009, p. 301).

Movements are either A-movements or A-bar movements. In cases where an expression, such as an NP, is moved to a position that can only be occupied by argument expressions, such as the case of passivization, A-movement occurs, whereas in cases where an expression, such as a WH-phrase, is moved to a position that can be occupied by both arguments and adjuncts, A-bar movement occurs (Radford, 2004). Another type of syntactic movement is headmovement, such as the cases where a V moves to I (Hawkins, 2001). 
Movement can occur both overtly (i.e. before spell-out) and covertly (i.e. after spell-out at LF). Feature checking triggers WH-movements, and one of the major characteristics of movements is the resultant chain that is formed between the moved WH-phrases (i.e. head of the chain) and the traces left behind by such movements (i.e. foot of the chain). The syntactic form of movement acts as a distinguishing factor among languages and, as a result, differs from language to language. Whereas in some languages like Japanese and Chinese, questions are formed without movement, in others, such as English, they require movement. Variable movements exist in other languages such as Turkish (Cook, 1993).

Movements are constrained by a UG principle termed subjacency (Radford, 1997). Subjacency, which was formulated by Chomsky in the late 1970s, refers to the syntactic constraints that block the movement of a unit if that unit crosses more than one bounding node. WH-movement is constrained by subjacency and refers to the movement of WH-forms to the beginning of a sentence or even a clause resulting in the formation of WH-traces. The extracted constituents make short-step moves because long moves give rise to ungrammaticality in constructions.

\section{WH-Movement in English and Persian}

Whereas IPs and NPs (DPs) are the bounding nodes in English, NPs and CPs are the bounding nodes in Persian. Hence, WH-movement must be, in English, to the nearest empty CP to avoid subjacency violations, whereas it must be, in Persian, to the nearest empty IP. Subjacency is an example of "subtle parameter variation" that extends far beyond L2 input and cannot be developed by L1 grammar. In bounding nodes, parametric variation is seen across languages (White, 1989, p. 111).

As for multiple WH-questions in English, the fact is that only one of the WH-expressions can move and be preposed. In such structures, the null complementizer at the top of the tree possesses both a WH feature, which necessitates the existence of a WH-expression, and an EPP feature, which requires $\mathrm{C}$ to have a WH-specifier. To fulfill its function, $\mathrm{C}$ attracts the closest WH-expression that it c-commands based on a UG principle named attract closest principle (ACP); that is, "A head which attracts a given kind of constituent attracts the closest constituent of the relevant kind" (Chomsky, 1998, 1999, 2001, pp. 198-200).

At times, only a WH-word, and not a WH-phrase, moves to form interrogatives without auxiliary movement, but, at other times, a sentence involves both the movement of a WH-phrase and an auxiliary. When a WH-quantifier moves to the sentence-initial position, its accompanying noun must move with it. In other words, the complement of a WHquantifier must always be pied-piped along with it. Hence, "main-clause questions are CPs headed by a $\mathrm{C}$ which carries [TNS, WH, EPP] features" (Radford, 2004, p. 170).

Operator movements in English are triggered by the feature strength, and the moved operator expressions leave behind a trace at their extraction sites. English is a language where the WH-feature of probe is strong; hence, the noninterpretable feature of the probe attracts its interpretable counterpart on goal overtly, that is before spell-out (Radford, 1997).

Upon reaching LF, the checking process checks and deletes the noninterpretable formal features, which have no semantic content, because such features are the viruses of the system, unlike the interpretable formal features that are reserved and interpreted. WH-phrases either move to check (i.e. the operation Attract, or rather Enlightened SelfInterest) or to be checked (i.e. the operation Greed). The feature of probe is weak in Persian; hence, the uninterpretable feature of the probe attracts its interpretable counterpart on goal covertly at LF. Weak features are more economical than strong features, an issue which is called procrastinate (i.e. languages tend to delay movement as much as possible). Unlike overt WH-movement in such languages as English that leaves behind a trace subject to the empty category principle, in languages with covert WH-movement such as Persian, where a WH-word is in deep structure, the ECP is irrelevant due to the nonexistence of traces (Lotfi, 2003).

In some languages where WH-forms are not preposed, such as Persian, WH-forms are called in-situ. Unlike English that is an SVO language, Persian is an SOV language where WH-movement is by no means mandatory, neither in single WH-movement sentences nor in multiple WH-movements. Hence, optionality applies to such WH-movements. Unlike English, Persian WH-movement is not triggered by a WH-feature, but rather a totally syntactic feature.

Persian is a topic-prominent language, but topicalization does not occur in it in cases where, for example, the whole sentence is in focus. Unlike English, the spec-TP position is not a subject position because neither raising to subject nor overt or covert expletives exist in Persian. One of the major issues that justifies the existence of spec-TP is the existence of a background topic.

Persian WH-arguments can either move or remain in-situ that, per se, serves as an instance of scrambling and the cause of change in interpretation; that is, when the WH-phrase remains in-situ, such as the case where it remains in VP, it asks for information-based interpretation, whereas in cases where it moves into the spec-focus position, it asks for contrastive-based interpretation; hence, in the latter case, the speaker has a set of options in mind and wonders which one will be chosen by the listener.

Many of the UG principles are parameterized because they function with varying degrees of effects in different languages. As for the principle of subjacency, certain construction types are islands; that is, extraction is impossible out of them. Such syntactic islands fall into four categories, namely object noun complements, subject noun complements, complex NPs, and WH-islands. Accordingly, certain general constraints limit the freedom of the WH-movement rules 
such as the A-over-A condition, subject condition, the complex noun phrase constraint (CNPC), and WH-island constraint. All of these constraints can be reduced to the cases of subjacency (White, 1988).

\section{Grammaticality Judgement Tasks}

Davies and Kaplan (1998) maintain that GJ tasks have started to be constantly used in L2 research since the mid1970s. Moreover, the extended standard theory has been of immense effect in the development of GJ tasks because such a theory, which was a version of TG and was developed in the mid-1970s, differed from its preceding standard theory in that the extended version focused on the surface structure, and not the deep structure, as the structure where the semantic representations of sentences were determined, either wholly or in part. Hence, GJ tasks, whose primary focus had been on the surface structure of the presented sentences to be judged by the L2 learners, evaluated the L2 learners' judgements on the meaning-based surface structure of the presented sentences. The development of principles and parameters theory was also highly effective in the emergence of GJ tasks.

Whereas Selinker (1974) emphasized the importance of observable data in the investigation of L2 when L2 learners try to speak in L2 spontaneously, Corder (1973) focused on the importance of data that are elicited by force and believed that spontaneous speech was not enough. We, instead, need a means of determining learners' grammatical knowledge; hence, tasks can prove helpful in this regard, and GJ tasks are a way of reflecting on the L2 learners' mental processes.

Gass and Mackey (2000) delve further into the issue of GJ tasks and assert that the term knowledge relates directly to cognition; as a result, GJ tasks are used to uncover the true nature of L2 learners' cognition.

As for task components, Ellis $(1990,1991)$ asserts that the components of a task-based test are such things as the task itself, a procedure for the implementation of the task, and a measure of subjects' performance to assess their performance.

Mackey and Gass (2005) assert that it is technically wrong to use the term Grammaticality Judgement task instead of Acceptability Judgement task. We use the judgements of acceptability to make inferences about subjects' grammaticality because grammar is abstract; hence, we cannot ask about grammaticality directly. The main reason for the use of GJ tasks is to obtain sufficient evidence on which to base the conclusions gained on subjects' L2 knowledge.

White (1990) believes that we, in GJ tasks, include those structures that are fairly complex and simply might not arise in the normal course of conversations to tap the L2 learners' conscious knowledge of, for example, WH-movements. Researchers manipulate the sentence types to be included and try to investigate those various aspects of L2 knowledge on which the operation of UG might have effects by looking at L2 competence and production in a controlled way. It is important that L2 learners be made to reveal, directly or indirectly, whether they know the required knowledge by showing if they have knowledge of ungrammaticality because linguistic competence includes knowledge of ungrammaticality.

The important issue is that violating a universal such as subjacency because of low proficiency does not necessarily mean lack of UG, but only a difficult structure for the students to process.

One way of establishing whether L2 learners' competence includes knowledge that certain forms are impossible is by the use of grammaticality judgement (GJ) tasks, where learners are asked to judge the correctness or otherwise of various sentences (White, 1989, p. 58).

\section{METHODOLOGY}

This research employed the quantitative method of data collection and analysis; hence, the quantitative part is covered extensively in this article.

\section{A. Research Question and Hypothesis}

One research question and one hypothesis guided the quantitative investigation process:

(a) Research Question: Does EFL participants' proficiency level influence their performance on WH-questions?

(b) Research Hypothesis: There will be no relationship between proficiency level and EFL participants' performance on WH-questions.

\section{B. Participants}

This study was carried out with sixty female EFL university students, within the 19-30 age range, of the Islamic Azad University (Khorasgan Branch) participated in our study. Participants were randomly selected from the accessible EFL student population of the university and divided into two proficiency groups as determined by the Grammar and Listening Modules of the Oxford Placement Test (OPT) (2004). That is, thirty female participants in the LowIntermediate group with scores falling in the range of 131 to 139 out of 200, and thirty female participants in the HighIntermediate group with scores falling above 141 up to 200. Participants had been permanent residents of Iran and lived in Esfahan.

\section{Instrument}

The research instruments included four two-choice GJ tasks with the same number of WH-questions to tap female EFL participants' knowledge of forming WH-questions. The GJ tasks examined the effect of such an independent 
variable as L2 learners' proficiency levels in L2 on their grammatical performance while rendering WH-questions in the explicit written, implicit written, oral stimulus, and no stimulus GJ tasks where stimuli are presented in different forms to determine the effect of the independent variable on EFL participants' English grammatical performance in GJ tasks under different conditions and from different angles.

The first GJ task (i.e. explicit written GJ task) was a 30-question task based on which female EFL participants were instructed to determine whether the written WH-questions served as proper questions for their pertinent written stimuli that preceded such WH-questions four seconds ago in popping up on the laptop screen. The second GJ task (i.e. implicit written GJ task) was a 30-question task based on which female EFL participants were instructed to determine whether the written WH-questions were congruent with the pictures that preceded such WH-questions four seconds ago in popping up on the laptop screen. Having worn headphones over their ears, participants listened to the oral recording of stimuli four seconds prior to being presented with their pertinent responses in the oral stimulus GJ task. However, participants received no stimuli whatsoever in the no stimulus GJ task to determine if stimuli were of any effects at all in the grammatical performance of female EFL participants (see Appendices A, B, C, and D).

The four GJ tasks tested different cases of subjacency and included both grammatical and ungrammatical WHquestions of equal complexity, vocabulary, and structure. In addition, filler items were included in the four GJ tasks to blur the point of investigation in the research project. Participants were instructed to select only one of the two choices for each question, namely either acceptable or not acceptable. The GJ tasks investigated syntactic islands in English; that is, those construction types that are islands with respect to movement.

\section{ANALYSIS AND RESUltS}

The data were analyzed through the Statistical Package for the Social Sciences (SPSS) for Windows. The results are presented in view of the research question that guided the current study.

To address the research question the statistical test of two-way repeated measures ANOVA was employed for testing the null hypothesis in this study. Since the intention was to compare participants' performance on more than one GJ task, the repeated measures ANOVA was used. As a result, the overall performance of the High-Intermediate group was compared with the overall performance of the Low-Intermediate group. Each participant in both High- and LowIntermediate groups did all the four GJ tasks. Hence, there were eight sets of results to be compared with each other. Each group was analyzed separately using the repeated measures ANOVA to measure how a single group performed on multiple measures (i.e. the four GJ tasks) and to measure if the effects of those measures were independent.

Using the SPSS software package, we conducted computerized data analysis via running the robust statistical procedure of parametric repeated measures ANOVA to experimentally manipulate the independent variable in this study (i.e. L2 proficiency level) to determine its effect, if any, on the dependent variable (i.e. female EFL participants' performance on the four GJ tasks). We used the repeated measures design because participants of the two proficiency groups (i.e. 30 High-Intermediate and 30 Low-Intermediate participants) were measured under different conditions.

Having entered the obtained data for the two hypotheses into the variable SPSS data view window with their descriptive labels, we obtained the indispensable general tendencies in the data and the overall spread of the scores via analyzing measures of central tendency and variability, as shown in Table 1.

TABLE 1. SAMPLE DESCRIPTIVE STATISTICS

\begin{tabular}{lccc}
\hline & \multicolumn{4}{c}{ SAMPLE DESCRIPTIVE STATISTICS } & \\
\hline Independent Variables & $N$ & Mean & Standard Deviation \\
\hline LG_ORL_STIM & 30 & 16.00 & 3.991 \\
LG_EXP_WRI & 30 & 17.03 & 3.978 \\
LG_IMP_WRI & 30 & 15.93 & 2.947 \\
LG_NO_STIM & 30 & 15.97 & 4.165 \\
HG_ORL_STIM & 30 & 17.37 & 3.378 \\
HG_EXP_WRI & 30 & 17.60 & 2.811 \\
HG_IMP_WRI & 30 & 17.37 & 3.113 \\
HG_NO_STIM & 30 & 18.00 & 3.151 \\
\hline
\end{tabular}

The numerical values of mean indicated that HG-NO-STIM had performed better than the other seven independent variables because the mean value was weighted in its favor. HG-EXP-WRI was the second independent variable that had performed better than the other six variables, and the other two High-Intermediate independent variables were the third independent variables that had performed better than the other four Low-Intermediate independent variables; that is, HG-ORL-WRI and HG-IMP-WRI, which had the same mean values, showed the third best performance on the GJ tasks; hence, proficiency level was of effect in the performance of female EFL participants, and the High-Intermediate group performed better than the Low-Intermediate group in all the four of its performance types in the four GJ tasks. However, the question remains as to whether such differences in favor of the four performance types of the HighIntermediate group in the four GJ tasks were statistically significant. In cases where standard deviation values are smaller than mean values, such as the case in Table 1, mean values can better capture the behavior of the samples.

The level of significance (alpha level) set as the criterion and standard for rejection and acceptance in this study is $5 \%$ (.05). The within-subjects factors, as shown in Table 2, are the basis for the repeated measures analysis of each study. In this study, the dependent variables (i.e. 60 female EFL participants' performance types in the explicit written, 
implicit written, oral stimulus, and no stimulus GJ tasks) are measured repeatedly for all sample participants across a set of conditions.

The within-subjects factors in this study have four levels for each group due to their four administrations in the forms of four different GJ tasks over four weeks. Hence, the within-subject factors have four levels because measures (i.e. explicit written, implicit written, oral stimulus, and no stimulus GJ tasks) are taken twice per group over four weeks using the within-groups design.

TABLE 2.

WITHIN-SUBJECTS FACTORS

\begin{tabular}{lcc}
\hline Group & Treatment & Independent Variables \\
\hline 1 & 1 & LG-ORL-STIM \\
& 2 & LG-EXP-W RI \\
& 3 & LG-IMP-WRI \\
& 4 & LG-NO-STIM \\
2 & 1 & HG-ORL-STIM \\
& 2 & HG-EXP-WRI \\
& 3 & HG-IMP-W RI \\
& 4 & HG-NO-STIM \\
\hline
\end{tabular}

In order to determine the effects of the independent variable on the participants' dependent variable and see if these effects are significant, we used the multivariate tests, as shown in Tables 3, 4 and 5. We used the multivariate analysis of variance to assess the effects of treatment, group, and group-treatment interaction in terms of repeated observations of the same participants in two groups of different proficiency levels. The grouping variable of group, as shown in Table 3, is the multivariate test of the two-level independent variable of proficiency level that distinguishes the two groups. This effect was not significant, $\mathrm{F}(1,58)=4.08>2.983$, indicating that the two levels of proficiency (i.e. Highand Low-Intermediate proficiency levels) did not differ significantly from each other on the weighted aggregate in terms of having different effects on the High- and Low-Intermediate female EFL participants' performance in the four GJ tasks while rendering WH-questions.

TABLE 3.

Multivariate TESTS

\begin{tabular}{llcccc}
\hline & Effect & Value & $F$ & Hypothesis $d f$ & Sig. \\
\hline \multirow{2}{*}{ Group } & Pillai's Trace & .093 & 2.983 & 1.000 & .095 \\
& Wilks' Lambda & .907 & 2.983 & 1.000 & .095 \\
& Hotelling's Trace & .103 & 2.983 & 1.000 & .095 \\
& Roy's Largest Root & .103 & 2.983 & 1.000 & .095 \\
\hline
\end{tabular}

The grouping variable of treatment, as shown in Table 4, is the multivariate test of within-subjects factor; that is, the four-level independent variable of presenting four GJ tasks to the two groups over four weeks in a counterbalanced way. This effect was not significant either, $\mathrm{F}(1,58)=4.08>1.494$.

TABLE 4.

Multivariate TeSTS

\begin{tabular}{llllll}
\hline & Effect & Value & $F$ & Hypothesis $d f$ & Sig. \\
\hline Treatment & Pillai's Trace & .142 & 1.494 & 3.000 & .238 \\
& Wilks' Lambda & .858 & 1.494 & 3.000 & .238 \\
& Hotelling's Trace & .166 & 1.494 & 3.000 & .238 \\
& Roy's Largest Root & .166 & 1.494 & 3.000 & .238 \\
\hline
\end{tabular}

Tests of significance of the multivariate effects of group-treatment interaction, as shown in Table 5, describe the multivariate effects of the repeated measures factor and the interaction of the factor with group. In this case, neither of the effects was significant, $\mathrm{F}(1,58)=4.08>$, suggesting that there did not exist multivariate effects for both treatment and the group-treatment interaction in either of the proficiency groups. The last use of the three leading multivariate test criteria of group differences, as shown in Table 5, revealed that the effect of the interaction between group and treatment was by no means significant in three of the four tests. That is, neither group showed significant interactions between its proficiency level and treatment. Hence, proficiency level and treatment were of no effects on each other within different groups. 
TABLE 5.

MULTIVARIATE TESTS

\begin{tabular}{ccccc}
\hline Effect & Value & $F$ & Hypothesis $d f$ & Sig \\
\hline Group* Treatment Pillai's Trace & .096 & .959 & 3.000 & .426 \\
Wilks' Lambda & .904 & .959 & 3.000 & .426 \\
Hotelling's Trace & .107 & .959 & 3.000 & .426 \\
Roy's Largest Root & .107 & .959 & 3.000 & .426 \\
\hline \multicolumn{5}{c}{$\dagger p<.05$, one-tailed }
\end{tabular}

The repeated measures ANOVA, which compares participants' performance on more than one task, is a robust parametric test. One of the assumptions underlying parametric tests is that data points are independent, but this assumption does not hold for a repeated measures design because, in repeated measures design, data for different conditions have come from the same people, hence the relatedness of data from different experimental conditions. This issue gives rise to an additional assumption according to which the relationship between pairs of groups is equal, that is the variances of the differences between levels of the repeated measures factor are equal in a within-subjects design. This assumption is called sphericity. This assumption resembles the variance assumption homogeneity in betweensubjects ANOVA. The sphericity assumption should not be violated; therefore, the SPSS software package includes a procedure called Mauchly's test that determines if the assumption of sphericity has been violated. Mauchly's test uses the Chi-Square test to test the sphericity assumption. The Mauchly's test of sphericity, as shown in Table 6, and the epsilon multipliers are applicable to the univariate repeated measures tests of the treatment within-subjects effects as well as the treatment-group interaction within-subjects effects.

TABLE 6.

MAUCHLY'S TEST OF SPHERICITY

\begin{tabular}{lccccccc}
\hline & \multicolumn{4}{c}{ MAUCHLY'S TEST OF SPHERICITY } \\
Within-Subjects & \multicolumn{3}{c}{ Approx Chi- } & \multicolumn{4}{c}{ Epsilon } \\
Effect & Mauchly's W & Square & $d f$ & Sig. & Geisser & Feldt & Bound \\
\hline Group & 1.000 & .000 & 0 &. & 1.000 & 1.000 & 1.000 \\
Treatment & .772 & 7.177 & 5 & .208 & .869 & .962 & .333 \\
Group*Treatment & .770 & 7.233 & 5 & .204 & .872 & .966 & .333 \\
\hline
\end{tabular}

We ran the Mauchly's test to determine whether the condition of sphericity had been met; that is, it tested the hypothesis that the variances of the differences between conditions were equal. Table 6 shows the findings of running Mauchly's test for this study. There are cases where a repeated measures independent variable has only two levels, such as the case in this study where we have two levels for one of the independent variables (i.e. the High- and LowIntermediate proficiency levels) as shown in Table 6 for the within-subjects effect of group that has resulted in the violation of sphericity. Moreover, there are cases where the estimates computed by the SPSS software package are one (i.e. Mauchly's W=1.000), which indicates perfect sphericity. In addition, the resulting significance test cannot be computed, hence the value of (.000) for the Approx. Chi-Square test, the value of (0) for the degrees of freedom, and a blank space for the significance.

If Mauchly's test statistic is significant (i.e. a probability value less than .05), such as the case for the effect of group in Table 6, it indicates the existence of significant differences between the variance of differences, and, as a result, the violation of sphericity ensues; in this case, one cannot trust the F-ratios. If, on the other hand, Mauchly's test statistic is nonsignificant (i.e. a probability value more than .05), such as the cases for the effects of treatment, and the interaction between group and treatment, it indicates lack of significant differences between the variance of differences, and, as a result, the observance of sphericity.

In cases where the sphericity assumption is violated, several corrections can be applied to produce a valid F-ratio. These corrections adjust the degrees of freedom associated with the F-value. The degrees of freedom are reduced in all cases based on an estimate of how spherical the data are. The result of reducing the degrees of freedom is making the Fratio more conservative; that is, the F-ratio has to be bigger than the probability value of .05 to indicate the existence of significant differences between the variance of differences. The corrections are three different estimates of sphericity that are made use of to correct the degrees of freedom (i.e. Greenhouse-Geisser, Huynh-Feldt, and Lower-Bound).

Epsilon is a descriptive statistic that indicates the degree to which sphericity has been violated. In cases where the epsilon value is more than 0.75 (i.e. $>0.75$ ), such as the case in Table 6 for the effect of group, we must use the HuynhFeldt correction, whereas in cases where the epsilon value is less than 0.75 (i.e. $<0.75$ ), we must use the GreenhouseGeisser correction.

In cases where Mauchly's test shows violation of sphericity, as shown in Table 6 for the section of group (i.e. the first row), this violation may be compensated by an epsilon adjustment. The condition of sphericity, unlike the section of group, was met in the sections of treatment, and group-treatment interaction. The numerator and denominator degrees of freedom in the F test are multiplied by epsilon. The repeated measures analysis conducted by the SPSS software package offers three epsilon estimates. The strength of a prediction is increased as the number of independent observations or degrees of freedom is increased. 
Since the epsilon values from Mauchly's test values are 1.000 (i.e. Table 6) for the section of group in the first row, and all of the three values are E $>0.75$ (i.e. Green-House Geisser $=1.000$, Huynh-Feldt $=1.000$, and Lower-Bound $=$ 1.000), we use the less conservative Huynh-Feldt corrected values to adjust both within-subject and between-subject degrees of freedom as shown in Table 7. Since there is violation of sphericity for the section of group, as shown in Table 6, we, using the Table 7, cannot reach a conclusion without a correction as to whether any significant differences exist between the two proficiency groups (i.e. High- and Low-Intermediate proficiency levels) while rendering WHquestions in the four GJ, hence the application of the Huynh-Feldt correction epsilon value, as shown in Table 7.

Applying the Huynh-Feldt correction epsilon value, we obtained no significant differences between the two proficiency groups in terms of their performance on the four GJ tasks. That is, the corrected F-ratio of Huynh-Feldt correction procedure showed the significance value of (.095) according to which High-Intermediate and LowIntermediate proficiency groups showed no significant differences in their performance in the four GJ tasks over four weeks while rendering WH-questions. Hence, we were incapable obtaining an understanding as to which proficiency group showed significant effects in its performance in the four GJ tasks while rendering WH-questions.

TABLE 7.

\begin{tabular}{|c|c|c|c|c|c|c|}
\hline & Source & $\begin{array}{l}\text { TS OF WITHIN-S } \\
\text { Type III Sum } \\
\text { of Squares }\end{array}$ & BJECTS & Mean Square & $F$ & Sig. \\
\hline \multirow[t]{4}{*}{ Group } & Sphericity Assumed & 109.350 & 1 & 109.350 & 2.983 & .095 \\
\hline & Greenhouse-Geis ser & 109.350 & 1.000 & 109.350 & 2.983 & .095 \\
\hline & Huynh-Feldt & 109.350 & 1.000 & 109.350 & 2.983 & .095 \\
\hline & Lower-Bound & 109.350 & 1.000 & 109.350 & 2.983 & .095 \\
\hline \multirow[t]{4}{*}{ Treatment } & Sphericity Assumed & 17.383 & 3 & 5.794 & 1.025 & .385 \\
\hline & Greenhouse-Geis ser & 17.383 & 2.606 & 6.671 & 1.025 & .379 \\
\hline & Huynh-Feldt & 17.383 & 2.886 & 6.023 & 1.025 & .384 \\
\hline & Lower-Bound & 17.383 & 1.000 & 17.383 & 1.025 & .320 \\
\hline
\end{tabular}

Having taken the two degrees of freedom into consideration to fit the critical values of the $\mathrm{F}$ distribution, we concluded that the calculated $\mathrm{F}$ in Table 7 for the case of treatment was F (1.025), was neither equal nor greater than the related critical value for the appropriate degrees of freedom, that is $\mathrm{F}(3,87)=2.76$; hence, the four GJ tasks in their eight treatments over four weeks were not considered statistically significant at the probability (.05) level. The same case held for the calculated F in Table 8 (i.e. F [1.026]) that was neither equal nor greater than the related critical value for the appropriate degrees of freedom, that is $F(3,87)=2.76$; hence, there was not a significant interaction between different groups and levels of treatments. Since the significance values of the F-ratios were more than .05 for treatment, as shown in Table 7, we were capable of saying that the effect of different treatments of the four GJ tasks was not significant.

TABLE 8.

TESTS OF WITHIN-SUBJECTS EFFECTS

\begin{tabular}{llccccc}
\hline & & \multicolumn{2}{c}{ Type III Sum } & & & \\
& Source & of Squares & $d f$ & Mean Square & $F$ & Sig. \\
\hline Group* & Sphericity Assumed & 16.317 & 3 & 5.439 & 1.026 & .385 \\
Treatment & Greenhouse-Geisser & 16.317 & 2.615 & 6.239 & 1.026 & .379 \\
& Huynh-Feldt & 16.317 & 2.898 & 5.630 & 1.026 & .384 \\
& Lower-Bound & 16.317 & 1.000 & 16.317 & 1.026 & .319 \\
\hline
\end{tabular}

Hence, the formal reporting of the statistical analysis for the two hypotheses in this study is as follows:

Mauchly's test indicated that the assumption of sphericity had been violated (chi-square $=.000, \mathrm{p}<.05$ ) of the type of group, therefore degrees of freedom were corrected using Huynh-Feldt estimates of sphericity $($ epsilon $=1.000)$. Mauchly's test indicated that the assumption of sphericity had not been violated (chi-square $=7.177, \mathrm{p}>.05$ ) of the type of treatment, therefore degrees of freedom were not corrected. Mauchly's test indicated that the assumption of sphericity had not been violated (chi-square $=7.233, \mathrm{p}>.05$ ) of the type of Group*Treatment, therefore degrees of freedom were not corrected. The results show that the performance scores of the two proficiency groups (i.e. HighIntermediate and Low-Intermediate proficiency groups) in the four Grammaticality Judgement tasks (Explicit Written, Implicit Written, Oral Stimulus, and No Stimulus Grammaticality Judgement tasks) did not differ significantly, and, as a result, the hypothesis was not rejected, Group $\mathrm{F}(1.000,29.000)=2.983$, P>.05; Treatment $\mathrm{F}(3,87)=1.025$, p>.05; Group*Treatment $\mathrm{F}(3,87)=1.026, \mathrm{P}>.05$.

\section{DisCuSSION AND CONCLUSIONS}

In view of the findings of previous research (Schachter, 1988; Bley-Vroman, Felix \& Ioup, 1988; White, 1990), the observed non-significant differences between the grammatical performance of High- and Low-Intermediate EFL participants can be attributed to the profound influence of UG in EFL participants' SLA process and the insignificant influence of EFL participants' L1 in their L2. In addition, in cases where L2 learners' L1 does not resemble their L2, 
such as the case in this study where Persian WH-questions do not resemble English WH-questions, L2 learners' observance of subjacency could only be due to UG. Moreover, L1 is not the only source of the learners' UG-like knowledge, and UG principles remain available in adult L2 acquisition. Hence, subjacency is a part of the L2 learners' unconscious knowledge, or rather grammatical proficiency, although it may not be consistently obeyed. Analyses of the results attained via other research projects (Clahsen \& Muysken, 1986; White, 1996) claim no access to UG at all in L2, a conclusion that stands in sharp contrast to the findings of his study.

Lack of support for this conclusion was provided by such research projects (Schachter, 1989, 1990; White, 1996; and Gass \& Mackey, 2000) according to which learners fail to recognize violations of UG principles, such as subjacency, unless these principles also operate in their L1; further, L2 proficiency level is indeed of significant effects on the grammatical performance of L2 learners in GJ tasks because L2 learners are constrained by their native language patterns, and the limited proficiency of learners operating in their L2s may influence the content of the recalls (i.e. it is possible for the students not to be able to understand or even verbalize the full extent of what they were thinking), hence the important and significant role and effect of L2 learners' L1 and L2 proficiency level on their grammatical performance in L2 given such findings, an issue which can also strongly indicate the significant transfer of L2 learners' L1 in their L2 grammatical performance.

In view of the findings of recent research on proper ways of tapping L2 learners' performance data (Hawkins, 2001 and White, 1989), the use of four different types of GJ tasks in this study can hardly be experimentally supported because L2 learners' performance data are indirect reflections of their grammatical competence, and that a difference exists between L2 learners' competence and their performance. In addition, when L2 learners use their L2 knowledge, as in GJ tasks, they reflect not only their interlanguage but also their performance variables that are not necessarily considered to be parts of their competence. The act of designing a proper method, such as GJ tasks, for tapping the L2 learners' knowledge of subjacency is quite challenging because having L2 knowledge does not necessarily mean being able to use that knowledge properly because its use is condition-based. Accordingly, GJ tasks cannot be apt testing instruments for tapping L2 learners' grammatical competence and grammatical proficiency because L2 learners' competence cannot be directly tapped, and we, as researchers, can merely use L2 learners' performance in GJ tasks to gain slight insights into their competence. Performance data are complex because samples may involve more than one grammatical property. Hence, the stance adopted in such research projects (Han \& Ellis,1998; and Dekeyser, 2003) towards the inability of GJ tasks in purely measuring implicit or explicit knowledge holds true; otherwise, the High- and Low-Intermediate female EFL participants might have shown significant differences in their grammatical performance, and the effects of their L1 transfer in their L2 grammatical performance would have been significant. GJ tasks can prove to be of effective research applications in such psychological arenas as measuring L2 learners' degree of reaction time spent while rendering WH-questions, and the like.

Since the performance of High- and Low-Intermediate EFL participants did not differ from each other significantly, we can infer that both of the proficiency groups may have used nearly all the strategies identified in the research projects conducted in this regard (Ellis, 1991 and Davies and Kaplan, 1998) while taking the four GJ tasks; that is, feel, rehearsing, rehearsing alternate versions, trying to access explicit knowledge, using analogy, evaluating sentences, and guessing. However, we would have expected the Low-Intermediate group to be using the feel and translation strategies more than the High-Intermediate group due to their lower L2 proficiency level.

\section{A. Limitations and Recommendations for Future Research}

Having drawn the final conclusions from the findings of this study, it is important to delimit the scope of their generalizability by outlining some important limitations. The first limitation concerns the participant samples. It should be kept in mind that the selected female EFL participants, who were university students, had had an extensive background in English grammar and a high metalinguistic understanding of the syntactic structures of English. For this reason, generalizing the findings emanated from this study to other populations of ESL and EFL learners will not be appropriate, such as those instructed and uninstructed who are of lower proficiency or lack the required metalinguistic competence.

Further, the drawn conclusions regarding the EFL participants should by no means be generalized to environments other than the ones from which the samples were drawn because they may differ substantially in several aspects, such as their English curricula, the methodology of teaching grammar or pragmatics, the intensity of the programs, and the like.

In addition, the use of more balanced testing instruments in the research process would have strengthened the validity of the observed results and could have provided further insights into potential L1 influences on the issues investigated. Furthermore, several replications of the study can further substantiate the reported results.

The importance of this study necessitates conducting research into the other aspects of UG focusing on the effects of such issues as modality, explicitness, implicitness, and congruency on the grammatical performance of L2 learners while rendering WH-questions in different GJ tasks such as the ones used in this study. Moreover, the current study can be replicated in cases where participants' L1 is any language but Persian because there is a distinct probability that L2 researchers find unexpectedly significant differences in the performance of their participants in the four GJ tasks.

\section{B. Theoretical Implications}


The findings of this study have consistently provided empirical support for the arguments regarding a lack of relationship between L2 learners' proficiency levels and their cognitive processing capabilities while rendering WHquestions because improvement in proficiency level by no means leads to deep language processing. In addition, the findings support the fact that EFL participants' mental representations of L2 knowledge are indeed structured, hence the verification of UG-based theories. L2 Learners do utilize rule- and exemplar-based knowledge while rendering GJ tasks.

The other theoretical implication of this study is that GJ tasks cannot be of practical applications within the framework of measuring L2 learners' grammatical competence in terms of syntactic knowledge partly because knowledge about grammaticality, ungrammaticality, ambiguity, and other subtle and complex phenomena goes far beyond primary linguistic data. However, GJ tasks can assist SLA researchers with achieving efficiencies in terms of measuring and analyzing L2 learners' RT.

\section{Pedagogical Implications}

Overall, the findings of this study suggest that classroom teachers can assist L2 learners of different proficiency levels with developing a constructive understanding of the nature of WH-movement in English as well as appreciating and establishing cognitive-semantic relationships between different explicit-implicit and written-oral instructive stimuli and their respective responses via improving the techniques and principles underlying the current pedagogical practices.

In addition, classroom teachers can adopt similar strategies for designing syllabi to ensure L2 learners' mastery over the conceptual processes required for properly using different subjacency cases in unplanned discourse. Such teachers can also adopt similar strategies for developing curricula for teaching the cases of subjacency within the framework of explicit instruction, implicit instruction, written instruction (i.e. via using books), and oral instruction, irrespctive of L2 learners' proficiency at schools, colleges, and like academic settings. Teachers can even feel the urgency of developing cognitive-provoking teaching materials at schools, colleges, and like academic settings.

As for GJ tasks, classroom teachers are aware not to employ GJ tasks in pedagogical settings owing to their inability to distinguish between the cognitive processes made use of in processing diverse forms and modes of stimuli presentations by L2 learners of different proficiency levels.

\section{APPENDIX A: SAMPLE OF THE WH-QUESTION USED IN THE EXPLICIT WRITTEN GJ TASK}

David Brown made the claim that Bob Green had talked about ART.

About what did David Brown make the claim that

Bob Green had talked?

APPENDIX B: SAMPLE OF THE WH-QUESTION USED IN THE IMPLICIT WRITTEN GJ TASK

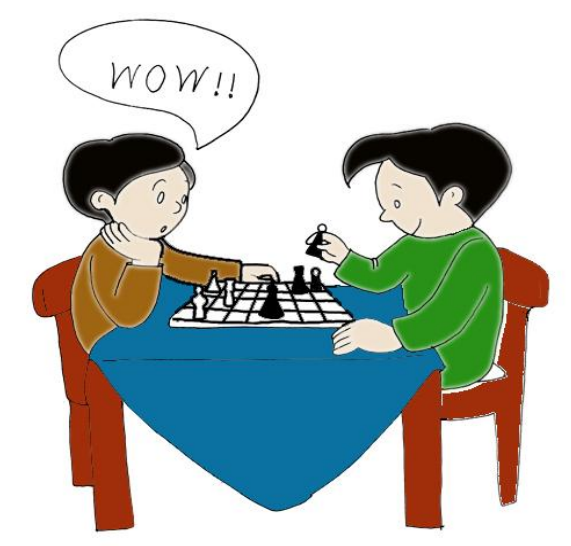

Bob Green's good play in what surprised whom?

\section{APPENDIX C: SAMPLE OF THE WH-QUESTION USED IN THE ORAL STIMULUS GJ TASK}

Having worn headphones over their ears, participants listened to the oral recording of a stimulus (a) four seconds prior to being presented with its pertinent response $(b)$ :

(a) David Brown has chosen for Bob Green a blue book in Law.

(b) Which major has David Brown chosen for Bob Green a blue book in? 
In this type of GJ task, participants receive no stimuli at all. They only receive a variety of WH-questions on their laptop screens.

Who has David Brown appointed a good candidate that can be chosen?

\section{REFERENCES}

[1] Ambar, M. (2001). WH-asymmetries. Elements. Minimaux de la Varietion Linguistique, 209-249. Universidade de Lisboa.

[2] Bley-Vroman, R., Felix, S., \& Ioup, G. (1988). The accessibility of Universal Grammar in adult language learning. Second Language Research: British Columbia.

[3] Chomsky, N. (1995). The Minimalist Program. Cambridge: MIT Press.

[4] Chomsky, N. (1998). Minimalist inquiries: The framework. MIT Working Papers in Linguistics, 15, 1-56.

[5] Chomsky, N. (1999). Derivation by phase. Ms. MIT.

[6] Chomsky, N. (2001). Beyond explanatory adequacy. Ms. MIT.

[7] Clahsen, H., \& Muysken, P. (1986). The availability of Universal Grammar to adult and child learners: A study of the acquisition of German word order. Second Language Research, 2, 93-119.

[8] Collins, P. (2006). Clause types. In: B. Aarts \& A. McMahon (Eds.), The handbook of English Linguistics (pp. 180-197). Blackwell Publishing.

[9] Cook, V. (1993). Linguistics and Second Language Acquisition. Macmillan Press: London.

[10] Corder, S. P. (1973). Introducing Applied Linguistics. Harmondsworth: Penguin.

[11] Davies, W.D., \& Kaplan, T.I. (1998). Native speaker vs. L2 learner Grammaticality Judgements. Applied Linguistics, 19/2, 183-203.

[12] DeKeyser, R. (2003). Implicit and explicit learning. In C.J. Doughty \& M.H. Long (Eds.), The handbook of Second Language Acquisition (pp. 313-348). Malden: Blackwell Publishing.

[13] Ellis, R. (1990). Grammaticality judgements and learner variability. In H. Burmeister and P. Rounds (Eds.), Variability in Second Language Acquisition: Proceedings of the tenth meeting of the Second Language Research Forum (pp. 25-60). Eugene, OR: University of Oregon.

[14] Ellis, R. (1991). Grammaticality Judgments and Second Language Acquisition. Studies in Second Language Acquisition, 13 (2), 161-86.

[15] Gass, S. M., \& Mackey, A. (2000). Stimulated recall methodology in second language research. Lawrence Erlbaum Associates.

[16] Gass, S. M., \& Selinker, L. (2008). Second Language Acquisition: An introductory course. NY: Routledge.

[17] George, A. (1989). How not to become confused about linguistics. In: A. George (Ed.), Reflections on Chomsky (pp. 90-110). Oxford: Blackwell Publishers.

[18] Hawkins, R. (2001). Second language syntax: A generative introduction. Oxford: Blackwell Publishing.

[19] Huddleston, R., \& Pullum, G. K. (2006). Coordination and Subordination. In: B. Aarts \& A. McMahon (Eds.), The handbook of English Linguistics (pp. 198-219). Blackwell Publishing.

[20] Isac, D.,\& Reiss, C. (2008). I-Language: An introduction to Linguistics as Cognitive Science. Oxford University Press.

[21] Lotfi, A.R. (2003). Intonation contours, yes/no questions, and minimalist syntax: A unitarianist perspective. Cognitive Sciences, 70-83. Esfahan: Azad University at Esfahan.

[22] Mackey, A., \& Gass, S. M. (2005). Second Language Research: Methodology and Design. NJ: Lawrence Erlbaum Associates.

[23] Matthews, P.H. (2007). Oxford concise dictionary of linguistics (2nd ed.). Oxford: Oxford University Press.

[24] Radford, A. (1997). Syntax. A minimalist introduction. Essex: Cambridge University Press.

[25] Radford, A. (2004). Minimalist syntax: Explaining the structure of English. Cambridge: Cambridge University Press.

[26] Radford, A., Atkinson, M., Britain, D., Clahsen, H., \& Spencer, A. (2009). Linguistics: An introduction (2nd ed.). Cambridge: Cambridge University Press.

[27] Ramchand, G. C. (2008). Verb meaning and the lexicon: A first-phase syntax. Cambridge University Press.

[28] Savignon, S. J. (2005). Communicative Language Teaching: Strategies and Goals. In E. Hinkel (Ed.), Handbook of research in second language teaching and learning (pp. 635-651). Mahwah, NJ: Lawrence Erlbaum Associates.

[29] Scalise, S., Magni, E., \& Bisetto, A. (Eds.) (2009). Universals of language today: Studies in natural language and linguistic theory. Springer.

[30] Schachter, J. (1988). Second Language Acquisition and its relationship to Universal Grammar. Applied Linguistics, 9, $219-235$.

[31] Schachter, J. (1989). Testing a proposed universal. In S. Gass \& J. Schachter (Eds.), Linguistic perspectives on Second Language Acquisition (pp. 73-88). Cambridge University Press.

[32] Schachter, J. (1990). On the issue of completeness in Second Language Acquisition. Second Language Research, 6, 93-124.

[33] Selinker, L. (1974). Interlanguage. In J. Richards (Ed.), Error analysis: Perspectives on Second Language Acquisition (pp. 31 54). London: Longman.

[34] Wasow, T. (2003). Generative Grammar. In M. Aronoff \& J. Rees-Miller (Eds.), The handbook of linguistics (pp. 295-318). MA: Blackwell Publishing.

[35] White, L. (1988). Island effects in Second Language Acquisition. In: S. Flynn \& W. O'Neil (Eds.), Linguistic theory in Second Language Acquisition (pp. 144-172). Dordrecht: Kluwer Academic Publishers.

[36] White, L. (1989). Universal Grammar and Second Language Acquisition. Philadelphia: John Benjamins Publishing.

[37] White, L. (1990). Second Language Acquisition and Universal Grammar. SSLA (PP. 121-133). USA: Cambridge University Press.

[38] White, L. (1996). Universal Grammar and Second Language Acquisition: Current trends and new directions. In: n.d. (Eds.), Handbook of Second Language Acquisition (pp. 85-120). Academic Press. 
Behrouz Nouri Samani His first name is Behrouz and his last name is Nouri Samani. He was born in Kuwait in 1974. He took his B.A. in English Translation from the Islamic Azad University (Esfahan Branch). Similarly, he took his M.A. in TESOL from the Islamic Azad University (Esfahan Branch). Finally, he took his PhD in TESOL from the Islamic Azad University (Esfahan Branch). His major fields of study are tesol and linguistics.

He has instructed such courses as Linguistics, and Techniques and Principles of Teaching at the Islamic Azad University (Esfahan Branch) for two semesters as an assistant professor. In addition, he has co-operated with a few Import-Export companies as both a translator of contractual and Law contexts, and as an instructor. He has had a couple of publications in CCSENET Journals. Lastly, his research interests include Linguistics, TESOL, Testing, and Psycholinguistics.

Ahmad Reza Lotfi He was born in Shahreza, Isfahan (IRAN) on September 6th 1965. His educational background includes a Ph.D. in English Language Teaching (ELT) from the Ph.D. Research Centre of Islamic Azad University in Tehran in 1997. He completed his doctoral dissertation entitled:" On the Significance of Negative Evidence in Second-Language Learning" under the supervision of Dr. A. Miremadi. Moreover, he received his M.A. in English Language Teaching (ELT) from the Tehran Branch of Islamic Azad University in 1991. He completed his master's thesis entitled:" The Approximative Method of Language Teaching" under the supervision of Dr. P. Birjandi. Further, he received his B.A. in the English in language (Translation) from the South Tehran Branch of Islamic Azad University in 1991. His major field of study is English and Persian linguistics.

His work experience includes being an English Lecturer, from 1991 up to 1997. He has also served as an English Translator and Interpreter in the fulfillment of Iranian compulsory military service. He is currently a member of the academic staff with the rank of Assistant Professor at the Islamic Azad University at Khorasgan (Esfahan) where he teaches Syntactic Argumentation and Discourse Analysis to Ph.D. candidates of ELT. In addition, he teaches Issues in Linguistics and Pedagogical Phonetics to M.A. students of ELT. Lastly, he has been a member of the Advisory Board of The LINGUIST list (Eastern Michigan University Wayne State University) from 2000 up to date. His previous publications include such articles as: Persian Wh-riddles (Amsterdam / Philadelphia: John Benjamins Publishing Company, 2003). In Multiple Wh-Fronting, C. Boeckx and K. K. Grohmann (eds), 161-186; Intonation contours, yes/no questions, and minimalist syntax: A unitarianist perspective (Cognitive Science, 2003). 1:70-83; Minimalist program revisited: Chomsky's strength to trigger movement (Germersheim: Proceedings of the 34th Linguistics Colloquium, 2002). R. Rapp (ed), 131-140. Frankfurt am Main. His current and previous research interests include such fields as the Generativist accounts of syntax, English and Persian linguistics, Second Language Acquisition, and Research in Generative Grammar. 